\title{
Neurodegenerative Diseases: Where To Go From Now? Thought Provoking Through $\mathrm{Ca}^{2+} / \mathrm{cAMP}$ Signaling Interaction \\ Leandro Bueno Bergantin*
}

Laboratory of Autonomic and Cardiovascular Pharmacology, Department of Pharmacology, Escola Paulista de Medicina, Universidade Federal de São Paulo (UNIFESP), São Paulo-SP, Brazil

\begin{abstract}
"Science is not always linear! Imagine this scenario: The $\mathrm{PhD}$ researcher and his supervisor are formulating their experiment. During the experiment course, there is on the bench a residual solution containing Verapamil, an L-type $\mathrm{Ca}^{2+}$ channel blocker (CCB). In a relapse, the $\mathrm{PhD}$ researcher decides to add this solution in an isolated smooth muscle preparation. The smooth muscle was prior relaxed with a drug that increased the CAMP cytosolic concentration. According to the classical receptor theory, addition of verapamil in the smooth muscle preparation should enhance the relaxation of the smooth muscle! To his surprise, the $\mathrm{PhD}$ researcher observed an incredible contraction of the smooth muscle! Perplexed with this result, the PhD researcher and his supervisor did not know how to explain this phenomenon immediately."
\end{abstract}

Keywords: $\mathrm{Ca}^{2+} / \mathrm{cAMP}$ signalling interaction; Neurodegenerative diseases

\section{An Enigma and of an Unusual History}

Indeed the previous described scenario happened during my $\mathrm{PhD}$ studies performed in the laboratory of Prof. Afonso CaricatiNeto at EPM-UNIFESP. According to the classical concepts of neurotransmission described since Sir Henry Dale [1], the release of neurotransmitters critically depends on the $\mathrm{Ca}^{2+}$ influx through L-type voltage-activated $\mathrm{Ca}^{2+}$ channels (VACCs), thus culminating in the elevation of $\mathrm{Ca}^{2+}$ concentration $\left(\mathrm{Ca}^{2+}\right)$ [2]. In consequence, this increases the release of neurotransmitter, finally enhancing the contraction of the smooth muscle. Considering these concepts, some authors showed that verapamil reduced the contraction of the smooth muscles $[3,4]$. Nonetheless, science is not always linear! Surprisingly, a study published in 1970's [5] described that, besides the classical effect of verapamil (in high concentrations) to reduce smooth muscle contractions, verapamil could also produce an apparent paradoxical increase of those contractions (in low concentrations) [5]. Isn't it strange, puzzling, a "calcium paradox"? This apparent puzzling result was validated in 1981 by French and Scott [6]. Additionally, another study Moritoki et al. [7] described that verapamil augmented the smooth muscle contractions, whose effect was replicated by diltiazem (another L-type VACC blocker). The authors concluded that this result could be attributed to an agonist effect of verapamil on L-type VACCs! Really?! Years later [8], another outstanding study appeared revealing that L- type VACCs blocker (verapamil) elicited similar increases of the contractions of the smooth muscle; the authors did not provide an elucidation for such apparent paradoxical observation. No one could blame on them!

Since 1990's, the Prof. Afonso's lab has also reproduced those previous observations: at lower concentrations, CCB produced a slight increase, while at higher concentrations the VACCs blocker caused a decrease of the smooth muscle contractions. In 2013 [9], during my $\mathrm{PhD}$ studies, we found an exciting discovery: as the high verapamil concentrations, various cAMP-stimulating compounds classically relax the isolated smooth muscle. Surprisingly, in the presence of cAMPstimulating compounds, the lower concentrations of verapamil caused an extraordinary augmentation of the smooth muscle contractions, instead of inhibiting them! In a "eureka minute", we concluded that the interaction between $\mathrm{Ca}^{2+}$ and cAMP signalling pathways $\left(\mathrm{Ca}^{2+} / \mathrm{cAMP}\right.$ signalling interaction) could properly solve these paradoxical results, including those observed since 1970's [5]. The original paper published by us in Cell Calcium in the year 2013, has appeared four times in Science direct top 25 hottest articles lists, including top 1 position [9].

\section{Which is the Relevance of this Discovery for Neurodegenerative Diseases?}

The rising increment in the life expectancy of the world's population has increased the fear about the age-related neurodegenerative disorders, such as Alzheimer's (AD) and Parkinson's (PD) diseases, and others. It is now well recognized that an imbalance of intracellular $\mathrm{Ca}^{2+}$ homeostasis contributes to the pathogenesis of neurological diseases such as the neurodegenerative diseases, including $\mathrm{AD}$ and $\mathrm{PD}$, and others. Our discovery of the role of $\mathrm{Ca}^{2+} / \mathrm{cAMP}$ signalling interaction in the neurotransmission, and neuroprotection, has subsidized the understanding of pathophysiology, and pharmacology, of the neurological and psychiatric diseases, opening a large pathway for the advancement of new pharmacological strategies (more effective) for the treatment of these disorders. In 2013, as described above, we discovered that the "calcium paradox" resulted from the increase of transmitter release from sympathetic neurons stimulated by CCB due to its modulatory action on the $\mathrm{Ca}^{2+} /$ cAMP signalling interaction [9]. In addition, we discovered that this modulatory action of CCBs both increases the intracellular levels of cAMP and reduces the $\mathrm{Ca}^{2+}$ influx, thus attenuating the neuronal death in the neurodegenerative diseases resulted from cytosolic $\mathrm{Ca}^{2+}$ excess. This novel proposal involves pharmaceuticals already approved, and

${ }^{*}$ Corresponding author: Leandro Bueno Bergantin, Laboratory of Autonomic and Cardiovascular Pharmacology, Department of Pharmacology, Escola Paulista de Medicina, Universidade Federal de São Paulo (UNIFESP), Rua Pedro de Toledo, 669 - Vila Clementino, São Paulo-SP, CEP: 04039-032, Brazil, Tel: 55115576 4973; E-mail: leanbio39@yahoo.com.br

Received November 08, 2017; Accepted November 13, 2017; Published November 18, 2017

Citation: Bergantin LB (2017) Neurodegenerative Diseases: Where To Go From Now? Thought Provoking Through $\mathrm{Ca}^{2+} / \mathrm{cAMP}$ Signaling Interaction. Brain Disord Ther 6: e125. doi: 10.4172/2168-975X.1000e125

Copyright: $\odot 2017$ Bergantin LB. This is an open-access article distributed unde the terms of the Creative Commons Attribution License, which permits unrestricted use, distribution, and reproduction in any medium, provided the original author and source are credited. 
Citation: Bergantin LB (2017) Neurodegenerative Diseases: Where To Go From Now? Thought Provoking Through $\mathrm{Ca}^{2+} / \mathrm{CAMP}$ Signaling Interaction. Brain Disord Ther 6: e125. doi: 10.4172/2168-975X.1000e125

clinically safe, from non-neurodegenerative therapy indications [10$18]$.

\section{Conclusion}

These concepts have been extensively discussed in several cited international articles of my own authorship ( $>40)$, book chapters and in an international book [2]. Thanks Prof. Afonso Caricati-Neto for always supporting me and my career.

\section{Acknowledgments}

Bergantin thanks the continued financial support from CAPES, CNPq and FAPESP (Bergantin's Postdoctoral Fellowship FAPESP \#2014/10274-3) and Prof Afonso Caricati-Neto for the continued support.

\section{References}

1. Burnstock G (2009) Autonomic neurotransmission: 60 years since Sir Henry Dale. Annu Rev Pharmacol Toxicol 49: 1-30.

2. Bergantin LB, Caricati-Neto A (2016) From discovering "calcium paradox" to $\mathrm{Ca}^{2+} / \mathrm{cAMP}$ interaction: Impact in human health and disease. Scholars Press $108 p$.

3. Hidalgo A Beneit J, Lorenzo P (1983) Effect of calcium antagonists on the response of the rat vas deferens to noradrenaline and field stimulation. Rev Esp Fisiol 39: 211-5.

4. Hata F, Fujita A, Saeki K, Kishi I, Takeuchi T, et al. (1992) Selective inhibitory effects of calcium channel antagonists on the two components of the neurogenic response of guinea pig vas deferens. J Pharmacol Exp Ther 263: 214-20.

5. Kreye VA, Luth JB (1975) Verapamil-induced phasic contractions of the isolated rat vas deferens. Naunyn Schmiedebergs Arch Pharmacol 287 Suppl: R43.

6. French AM, Scott NC (1981) A comparison of the effects of nifedipine and verapamil on rat vas deferens. $\mathrm{Br} \mathrm{J}$ Pharmacol 73: 321-323.

7. Moritoki H, Iwamoto T, Kanaya J, Maeshiba Y, Ishida Y, et al. (1987) Verapami enhances the non-adrenergic twitch response of rat vas deferens. Eur $\mathrm{J}$ Pharmacol 140: 75-83

8. Rae GA, Calixto JB (1989) Interactions of calcium antagonists and the calcium channel agonist Bay K 8644 on neurotransmission of the mouse isolated vas deferens. Br J Pharmacol 96: 333-340.

9. Bergantin LB, Souza CF, Ferreira RM, Smaili SS, Jurkiewicz NH, et al. (2013) Novel model for "calcium paradox" in sympathetic transmission of smooth muscles: role of cyclic AMP pathway. Cell Calcium 54: 202-212.

10. Caricati-Neto A, Garcia AG, Bergantin LB (2015) Pharmacological implications of the $\mathrm{Ca}^{2+} / \mathrm{cAMP}$ signaling interaction: from risk for antihypertensive therapy to potential beneficial for neurological and psychiatric disorders. Pharmacol Res Perspect 3: e00181.

11. Bergantin LB, Caricati-Neto A (2016) Challenges for the pharmacological treatment of neurological and psychiatric disorders: Implications of the $\mathrm{Ca}^{2+}$ cAMP intracellular signalling interaction. European Journal of Pharmacology 788: 255-260.

12. Bergantin LB, Caricati-Neto A (2016) Insight from "calcium paradox" due to $\mathrm{Ca}^{2+} / \mathrm{CAMP}$ Interaction: Novel pharmacological strategies for the treatment of depression. Int Arch Clin Pharmacol 2: 007.

13. Bergantin LB, Caricati-Neto A (2016) Novel insights for therapy of Parkinson's disease: Pharmacological modulation of the $\mathrm{Ca}^{2+} / \mathrm{cAMP}$ signalling interaction. Austin Neurol \& Neurosci 1: 1009

14. Bergantin LB, Caricati-Neto A (2016) Recent advances in pharmacotherapy of neurological and psychiatric disorders promoted by discovery of the role of $\mathrm{Ca}^{2+} / \mathrm{cAMP}$ signaling interaction in the neurotransmission and neuroprotection. Adv Pharmac J 1: 66

15. Bergantin LB, Caricati-Neto A (2016) New therapeutic strategy of Alzheimer's and Parkinson's diseases: Pharmacological modulation of neural $\mathrm{Ca}^{2+} / \mathrm{cAMP}$ intracellular signaling interaction. Asian Journal of Pharmacy and Pharmacology 2: $136-143$.

16. Bergantin LB, Caricati-Neto A (2016) Impact of interaction of $\mathrm{Ca}^{2+} / \mathrm{cAMP}$ intracellular signalling pathways in clinical pharmacology and translationa medicine. Clinical Pharmacology and Translational Medicine 1-4.

17. Bergantin LB, Caricati-Neto A (2016) Challenges for the pharmacological treatment of dementia: Implications of the $\mathrm{Ca}^{2+} / \mathrm{CAMP}$ intracellular signalling interaction. Avidscience 2-25.

18. Bergantin LB, Caricati-Neto A (2017) The discovery of the 'calcium paradox' due to $\mathrm{Ca}^{2+} / \mathrm{cAMP}$ interaction: Novel adventures for the pharmacotherapy of neurological/ psychiatric disorders. The Scientific Pages of Brain Disorders 1: 1-3. 